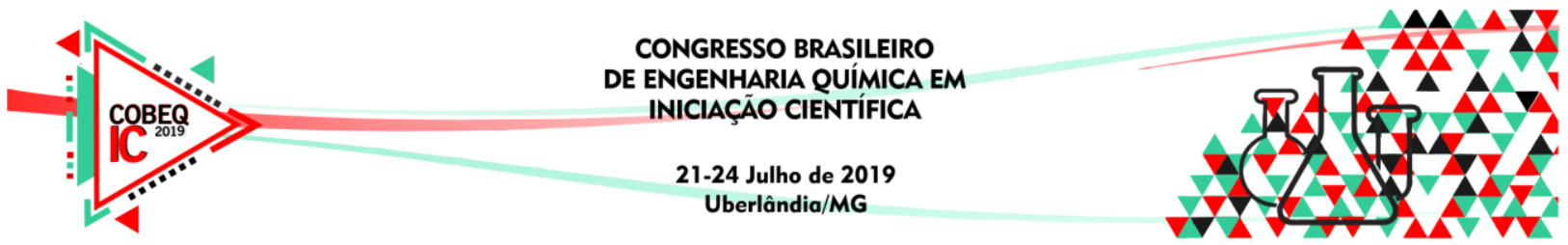

\title{
RETICULAÇÃO DE ESPUMAS DA BLENDA PVA/ALGINATO DE SÓDIO PARA APLICAÇÕES MÉDICAS
}

\author{
P. A. de ANDRADE ${ }^{1}$, J. E. de OLIVEIRA ${ }^{1}$ e P. H. S. CESAR ${ }^{2}$ \\ ${ }^{1}$ Universidade Federal de Lavras, Departamento de Engenharia \\ ${ }^{2}$ Universidade Federal de Lavras, Departamento de Química \\ E-mail para contato: paula.andradeeq@gmail.com
}

\begin{abstract}
RESUMO - O poli(álcool vinílico) (PVA) e o alginato de sódio (AlgNa) são considerados biomateriais por suas características de biocompatibilidade. $\mathrm{O}$ processo de reticulação promove a formação de estruturas macromolecular tridimensional com ligações cruzadas, podendo promover maiores estabilidades químicas dos compostos. O trabalho objetivou realizar o estudo de reticulação química na produção de espumas poliméricas da blenda PVA/AlgNa com glutaraldeído (GA) como agente reticulante. As espumas foram produzidas em diferentes proporções PVA:AlgNa $(\mathrm{m} / \mathrm{v}):$ 100:0, 75:25, 50:50, 0:100; e GA em concentrações de $0,150,0,075$ e $0,0375 \%$ (v/v), em solução ácida. O material foi caracterizado por espectroscopia na região do infravermelho com transformada de Fourier (FTIR), microscopia eletrônica de varredura (MEV) e ensaios de estabilidade em solução aquosa. Os espectros do FTIR apresentaram estiramento da ligação -OH como grupo funcional e estiramento -COC, indicando interações intermoleculares entre os polímeros da blenda, assim como da blenda com o reticulante. As micrografias apresentaram porosidades e interconectividades. Os ensaios de estabilidade, em solução aquosa, apresentaram alta capacidade de absorção de 18 vezes o seu volume inicial. As espumas poliméricas apresentam propriedades importantes para uso como biomaterial de aplicação como curativos.
\end{abstract}

\section{INTRODUÇÃO}

Durante o processo de cicatrização de feridas, curativos poliméricos são utilizados como barreiras físicas permeáveis a oxigênio e umidade, protegendo contra a ação de microrganismos. De acordo com sua natureza e aditivos podem, também, estimular o processo de recuperação tecidual. Diversos produtos como gazes, hidrogéis, espumas, hidrocolóides, colágeno, celulose, entre outros, são utilizados para estimular a cicatrização das feridas devido a sua influência na resposta celular local (Mogoşanu; Grumezescu, 2014).

Polímeros sintéticos são amplamente utilizados para aplicações biomédicas devido a propriedades como biocompatibilidade, biodegradabilidade e não toxicidade. Entretanto a aplicação desses polímeros individualmente no tratamento de feridas é limitada por algumas propriedades. A união de polissacarídeos com esses materiais poliméricos vem como uma solução para essa questão, onde as melhores propriedades químicas e biológicas de ambos são combinadas para a produção de curativos de desempenho superior. Os polissacarídeos mais 


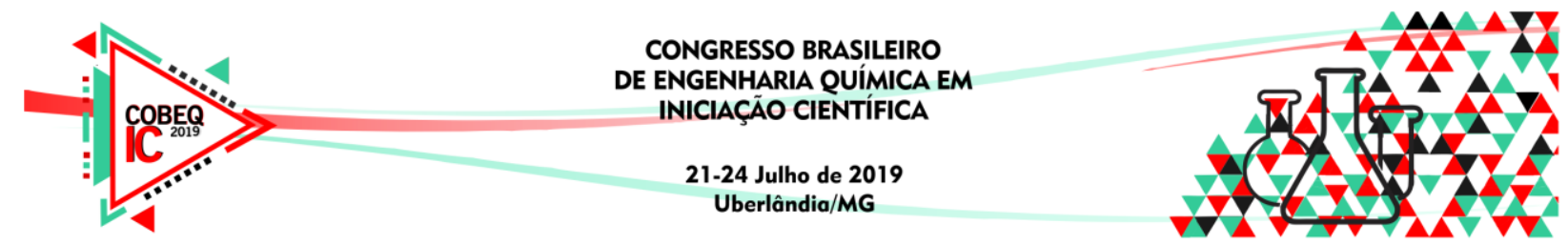

estudados para essa aplicação biomédica incluem quitosana, queratina, alginato de sódio (NaAlg), agarose e ácido hialurônico (Xiao Liu; Jia, 2018).

O alginato de sódio é um polissacarídeo natural linear, não ramificado, derivado de algas marrons. Esse material natural é biodegradável, biocompatível e pode absorver água ou fluidos corporais até 20 vezes o seu próprio peso, fornecendo, assim, um ambiente de cicatrização de feridas úmido. Estudos demonstraram que o NaAlg possui propriedades de cicatrização de feridas, sendo bom candidato como material de matriz para esse tipo de aplicação. Embora o alginato não possua propriedades antimicrobianas, aditivos bioativos podem ser adicionados ao material para torná-lo funcional (Rosa et al., 2018).

Atualmente o PVA é um material largamente utilizado em diversas áreas industriais. Recentes estudos estão voltados para o desenvolvimento de espumas poliméricas de PVA, o qual se destaca de outros por se tratar de um material suave, absorvente, de alta retenção, de porosidade controlada, inerte e biocompatível. Essas espumas são bons candidatos para procedimentos oftalmológicos, cirurgias refrativas, engenharia de tecidos e tratamento de feridas (Karimi; Navidbakhsh; Faghihi, 2014).

As espumas poliméricas são constituídas por duas fases: uma matriz polimérica sólida e uma fase gasosa derivada de um agente de expansão. As propriedades e características de uma espuma são definidas durante o processo de fabricação, onde ao mesmo tempo reações de reticulação e de formação dos gases de expansão ocorrem (Azevedo; Chávez; Rabello, 2010). A etapa de reticulação é de grande importância, pois é nela em que as propriedades físicoquímicas são determinadas. A reticulação possibilita a formação de uma estrutura macromolecular tridimensional com ligações cruzadas, o que garante uma maior estabilidade química para os compostos. O método de reticulação química ocorre por meio de uma recombinação de macroradicais, onde os grupos hidroxilas presentes no PVA podem formar fortes interações, como ligação de hidrogênio e ligações primárias covalentes, com os agentes reticulantes. Ao serem utilizados, em catálise ácida, formam pontes acetais com os grupos hidroxilas. As limitações encontradas nesse método estão relacionadas com a não uniformidade da matriz obtida e ao fato de que os agentes reticulantes podem permanecer em quantidades residuais, sendo tóxicos em alguns casos (Sadahira; Souza; Mansur, 2007).

Após o processo de reticulação o polímero obtido possui uma estrutura distinta da inicial, sofrendo alterações em diversas de suas propriedades. Neste contexto, este trabalho teve como objetivo analisar a influência dos processos de reticulação na blenda polimérica, estruturada como espuma, de PVA/AlgNa, utilizando uma concentração de agente reticulante, o glutaraldeído, que não seja tóxica. Este estudo visa contribuir para a aplicação do material obtido na área médica, especificamente na forma de curativos do tipo espuma.

\section{MATERIAIS E MÉTODOS}

Para a realização do projeto foram empregados PVA (Kuraray America Inc.) e Alginato de Sódio (ISOFAR) como matrizes poliméricas e glutaraldeído como agente reticulante. Foram necessários para a caracterização do material o uso de espectrofotômetro na região do infravermelho por transformada de Fourier e microscópio eletrônico de varredura. Utilizaram- 


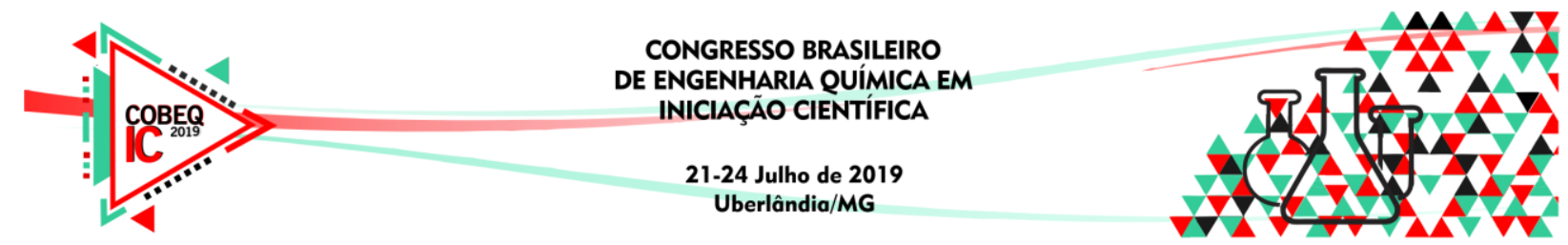

se também materiais laboratoriais, cedidos pelo Laboratório de Bioquímica da Universidade Federal de Lavras, como balança analítica, béqueres, pipetas, entre outros.

Para o preparo das esponjas inicialmente foi necessário dissolver o alginato de sódio (a 3,5\% m:v) em água MiliQ, à temperatura ambiente e sob constante agitação. Em um segundo béquer foi preparada uma solução de PVA (a 3,5\% m:v), em temperatura de $90^{\circ} \mathrm{C}$ para dissolução e, em seguida, a solução foi resfriada até atingir $40^{\circ} \mathrm{C}$. Então, ambas as soluções foram misturadas de modo a se obter uma solução polimérica nas combinações desejadas. As proporções utilizadas foram PVA:AlgNa (m/v): 100:0, 75:25, 50:50, 0:100. Para a etapa de reticulação, reduziu-se o $\mathrm{pH}$ com $\mathrm{HCl} 2 \mathrm{M}$ até que ficasse em torno de 2 . O glutaraldeído, então, foi adicionado em concentrações de 0,150, 0,075 e 0,0375\% (v/v). Em um molde de silicone $\left(4 \mathrm{~cm}^{2}\right)$, foi vertido $1,75 \mathrm{~mL}$ da solução polimérica, a qual foi congelada à $-80^{\circ} \mathrm{C}$, por 1 hora. Uma vez congeladas, as espumas foram liofilizadas por 24 horas.

A caracterização dos espectros no infravermelho foi realizada no Laboratório de Espectroscopia na Região do Infravermelho, utilizando o Espectrômetro Varian-660 IR (marca Pike), com transformada de Fourier, por reflectância total atenuada (ATR) na região de 4000-400 $\mathrm{cm}^{-1}$. As condições utilizadas foram de 16 scans e resolução de $4 \mathrm{~cm}^{-1}$.

A morfologia dos filmes foi investigada por MEV no laboratório de Microscopia Eletrônica e Análise Ultraestrutural (LME), utilizando o Microscópio Zeiss EM 109, com operação na voltagem de $20 \mathrm{kV}$ e ampliação de 200x. As análises de MEV foram realizadas tanto na superfície como na seção transversal a partir da fratura em nitrogênio líquido. Previamente às análises, as amostras foram recobertas como uma fina camada de ouro.

Os ensaios de estabilidade em solução aquosa foram feitos com a medida de intumescimento das espumas. $\mathrm{O}$ grau de intumescimento (GI) foi determinado considerandose 3 diferentes amostras, de massas aproximadas e com tamanho médio de $0,25 \mathrm{~cm}^{2}$ cada, para cada combinação polimérica seca. $O$ peso das amostras secas foi obtido e, posteriormente, elas foram imersas em um recipiente contendo água destilada em temperatura ambiente. Em tempos pré-determinados, as espumas foram retiradas do líquido, a água superficial foi removida com papel filtro e a massa final foi determinada. O cálculo do grau de intumescimento foi realizado segundo a equação 1 .

$$
G I=\frac{(M i-M o)}{M o}
$$

Onde: $G \mathrm{I}=$ Grau de intumescimento, $M i=$ Massa intumescida, $M \mathrm{o}=$ Massa seca.

\section{RESULTADOS E DISCUSSÃO}

A espectroscopia na região do infravermelho foi utilizada para a caracterização dos grupos funcionais típicos presentes nas espumas confeccionadas. Na figura 1 encontram-se os espectros das amostras poliméricas, na concentração 0,075\% de GA, e alguns dos principais grupos funcionais identificados pelos números de onda. 


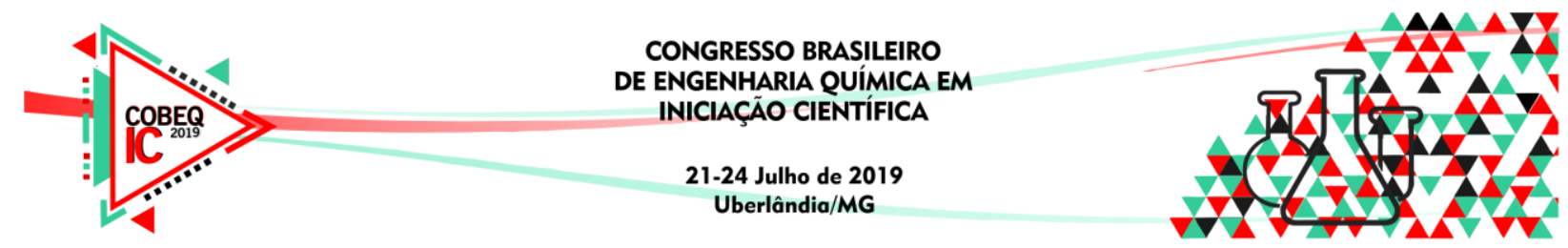

Figura 1 - Espectro infravermelho para diferentes proporções da blenda PVA:AlgNa com $0,075 \%$ GA.

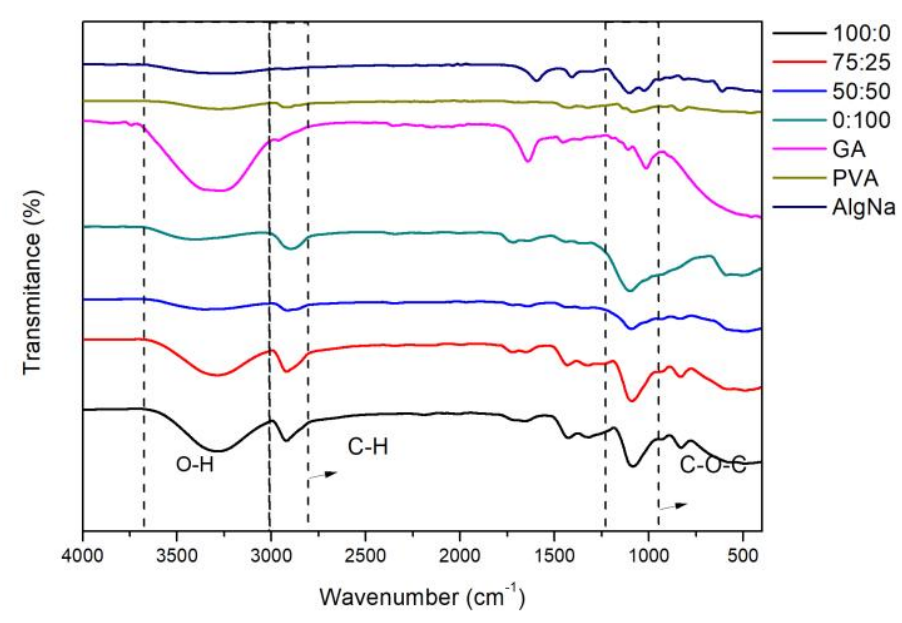

Através dos espectros do FTIR foi possível identificar bandas como a do estiramento da ligação - OH como grupo funcional (entre 3000 e $3550 \mathrm{~cm}^{-1}$ ) e o estiramento de grupos acetais (ligação - COC, em $1131 \mathrm{~cm}^{-1}$ ), ambas presentes nos componentes utilizados. No pico de $1640 \mathrm{~cm}^{-1}$ do espectro do GA é identificada a carbonila $(\mathrm{C}=\mathrm{O})$, característica dos aldeídos. Já em $1410 \mathrm{~cm}^{-1}$ e $1597 \mathrm{~cm}^{-1}$, do espectro de AlgNa, encontram-se as bandas originadas de deformações axiais, simétrica e assimétrica respectivamente, do íon - $\mathrm{COO}^{-}$.

A comparação da relação de intensidades entre duas bandas pode ser um indicativo de mudanças sofridas na estrutura molecular de um composto. Ao adicionar o agente reticulante pode-se observar um aumento na relação de intensidade de transmitância (I) dos picos referentes ao grupo acetal pelo grupo hidroxila. No PVA puro a relação $\mathrm{I}_{\mathrm{COC}} / \mathrm{I}_{\mathrm{OH}}$ foi de 1,03 , enquanto que no tratamento com a reticulação $0,075 \%$ de GA esse número eleva-se a 1,23. O aumento também ocorre ao reticular o alginato de sódio e quando se compara o PVA puro (100:0) com a blenda 75:25, reticulados com a mesma \% GA. Essa constatação é um indicativo da reação das hidroxilas, presentes no PVA, no AlgNa e no GA, e formando pontes acetais, o que comprova a reticulação do material baseada no mecanismo proposto por Trampus (2016).

A morfologia das estruturas porosas obtidas foi observada utilizando-se a análise de MEV. Ao analisar a seção transversal das amostras observou-se a presença de interconectividade entre os poros. Pôde-se observar, através da área média dos poros, que os diferentes tratamentos das blendas poliméricas reticuladas apresentaram valores bem diversos. Cada tamanho médio pode ser compatível e próprio para algum tipo de célula. Para a utilização das espumas como curativos médicos, a espuma com a melhor área média de poro seria a que permitisse a migração e proliferação das células do tecido epitelial. Para esse tipo de determinação seria necessária uma análise de cultura biológica.

Foi analisada também a porcentagem superficial ocupada pelas estruturas porosas, onde se encontraram valores de 16 a $42 \%$, indicando grande volume de poros nas estruturas. A 


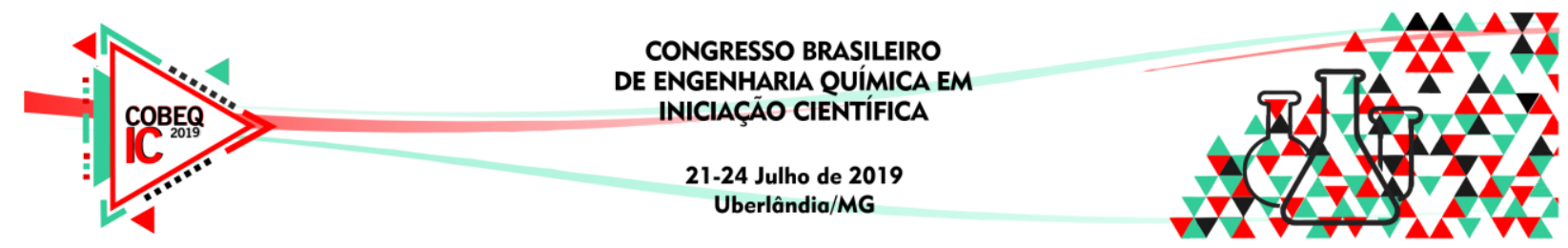

presença de uma maior porcentagem de poros facilita a absorção de fluidos e exsudados liberados pelo processo de cicatrização, além de permitir a passagem de oxigênio para os processos biológicos.

$\mathrm{Na}$ realização dos ensaios de estabilidade em solução aquosa as massas das amostras intumescidas foram coletadas até que houvesse uma estabilidade nos valores. Os resultados para o grau de intumescimento (GI) encontram-se demonstrados na Figura 2. Esses valores indicam uma alta capacidade de absorção das espumas poliméricas, provavelmente derivada da penetração do líquido nas estruturas porosas e da interação da água (através de ligações de hidrogênio) com sítios reativos de $-\mathrm{OH}$.

Figura 2 - Grau de intumescimento em diferentes níveis de reticulação.

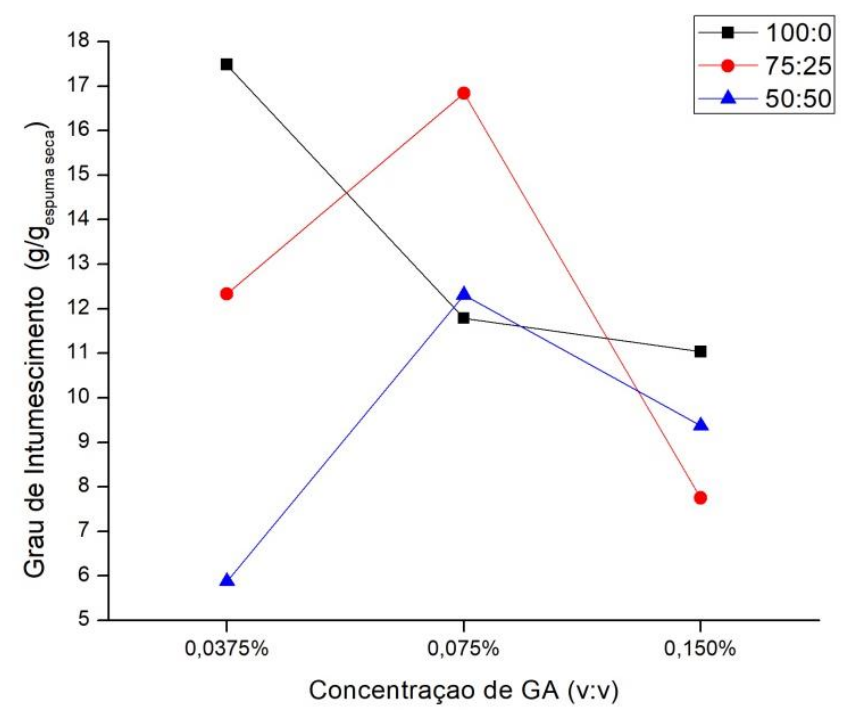

O efeito do agente reticulante no intumescimento tem sido muito estudado em sistemas macromoleculares. Foi observada uma diminuição do GI com o aumento da porcentagem de reticulação, mas também quando essa porcentagem é baixa. A primeira constatação pode ter decorrido da possível maior interação entre os polímeros e o agente reticulante, favorecendo a formação de maior número de pontos de reticulação que competem com a água pelos mesmos sítios reativos (LIMA et al., 2007). Já para a baixa porcentagem de reticulação, o reticulante pode não ter formado estruturas tridimensionais com ligações cruzadas efetivamente. Sendo assim as ligações intermoleculares permanecerão de certa forma, mais compactas e o volume livre no polímero será suficientemente baixo para evitar uma maior penetração da água em sua estrutura. Na blenda polimérica 100:0 isso não ocorre, o que sugere que ouve a formação efetiva de uma estrutura tridimensional na reticulação do PVA puro.

\section{CONCLUSÃO}

A confecção das espumas poliméricas, utilizando a blenda PVA/AlgNa e glutaraldeído como agente reticulante, foi possível através da metodologia utilizada. Através da espectroscopia na região do infravermelho (FTIR) foi possível observar os grupos funcionais característicos de cada molécula e foram comprovadas as interações intermoleculares entre os polímeros da blenda, assim como dos polímeros com o reticulante. 


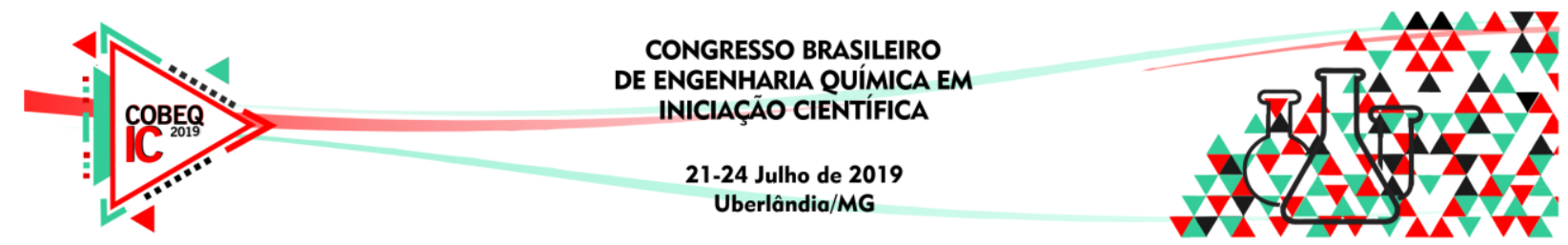

As imagens obtidas através da microscopia eletrônica de varredura permitiram a visualização da estrutura porosa do material. Pôde-se concluir que através do processo de reticulação química foi possível obter maiores porcentagens de área porosa. A seção transversal das amostras revelou a interconectividade dos poros, fator importante para a proliferação e regeneração de células.

Através do GI foi constatado que as espumas possuem uma alta capacidade de absorção aquosa, podendo absorver até 18 vezes o seu volume inicial, característica de grande importância para utilização das espumas como curativos, pois permite a absorção de fluidos e exsudados, a passagem de oxigênio para os processos biológicos, entre outros.

Vários fatores devem ser considerados para a determinação de uma melhor proporção de polímeros e agente reticulante para suas possíveis aplicações. De modo geral, a caracterização das espumas poliméricas indicou os materiais como bons candidatos para utilização no campo da medicina, apresentando propriedades essenciais para um bom curativo para feridas.

\section{REFERÊNCIAS BIBLIOGRÁFICAS}

AZEVEDO, J. B.; CHÁVEZ, M. A.; RABELLO, M. S. Efeito de Reticulante na Morfologia e Propriedades Físico-Mecânicas de Espumas Poliméricas Obtidas com EVA e EPDM. v. 20, p. 407-414, 2010.

KARIMI, A.; NAVIDBAKHSH, M.; FAGHIHI, S. Fabrication and mechanical characterization of a polyvinyl alcohol sponge for tissue engineering applications. Perfusion, v. 29, n. 3, p. 231-237, 20 maio 2014.

LIMA, A. M. F. et al. Influência da adição de plastificante do processo de reticulação na morfologia, absorção de aguá e propriedades mecânicas de filmes de alginato de sódio. Química Nova, v. 30, n. 4, p. 832-837, ago. 2007.

MOGOŞANU, G. D.; GRUMEZESCU, A. M. Natural and synthetic polymers for wounds and burns dressing. International Journal of Pharmaceutics, v. 463, n. 2, p. 127-136, mar. 2014.

ROSA, J. M. et al. Antimicrobial wound dressing films containing essential oils and oleoresins of pepper encapsulated in sodium alginate films. Ciência Rural, v. 48, n. 3, p. 1-5, 22 mar. 2018.

SADAHIRA, C. M.; SOUZA, A. N. DE; MANSUR, H. S. Caracterização dos hidrogéis do álcool polivinílico (PVA) processados por método químico e radiação gama. p. 10, 2007.

TRAMPUS, B. C. Estratégias baseadas em reticulação de polímeros para evitar perdas de circulação em poços de petróleo. [s.l.] Universidade Federal do Rio de Janeiro, 2016.

XIAO LIU, M.; JIA, G. Modern Wound Dressing Using Polymers/Biopolymers. Journal of Material Science \& Engineering, v. 07, n. 03, p. 7-10, 2018. 